\title{
A TICKET TO COFFEE: STAKEHOLDER VIEW AND THEORETICAL FRAMEWORK OF COFFEE TOURISM BENEFITS
}

\author{
ELENA CANDELO, CECILIA CASALEGNO, CHIARA CIVERA, AND GIACOMO BÜCHI
}

Department of Management, University of Torino, Torino, Italy

\begin{abstract}
This study is focused on the issue of agritourism in developing countries, which is a growing phenomenon and an understudied topic by the academic literature. By developing an investigation on coffee tourism based on multiple stakeholder perspectives around the subject, we contribute to further the debate over potentialities and benefits of coffee tourism development. We applied grounded theory methodology and through an iterated process involving literature review, a case study on Costa Rica, interviews with coffee experts, and a survey with European tourists, we designed a theoretical framework of the benefits that coffee tourism can have on both local farmers, who are vulnerable and lowpower stakeholders within the coffee supply chain, and on actual and potential coffee tourists. Our research pointed out that empowerment and cooperation, business diversification, sustainability, and creation of a destination image are the four main benefits for the local communities of farmers and their families and are also perceived to be creating favorable and attracting conditions for tourists.
\end{abstract}

\section{Key words: Agritourism; Coffee tourism; Vulnerable stakeholders; Developing countries; Grounded theory}

Introduction

The relevance and the potential of food and beverage $(\mathrm{F} \& \mathrm{~B})$ tourism is well recognized by scholars in the field of tourism management (Cheng, Hu, Fox, \& Zhang, 2012). Food tourism is said to be highly instrumental in regional development and value creation. Many studies have been developed to this end, particularly applicable to rural areas and $\mathrm{F} \& \mathrm{~B}$ products, such as wine and beer (Plummer, Telfer, Hashimoto, \& Summers, 2005; Sharpley \&
Telfer, 2015; Sun, Jansen-Verbeke, Min, \& Cheng, 2011). Agritourism and community tourism (LópezGuzmán, Sánchez-Cañizares, \& Pavón, 2011) is a niche tourism segment that involves experiencing life on working farms and developing related products for the commercial development of rural areas (Jaffee, 2014; Phillip, Hunter, \& Blackstock, 2010). In the vast literature on F\&B tourism, the majority of the studies have focused on the exploration of food tourism motivations, culture, authenticity, management, marketing practices, and destination 
orientation as described by Ellis, Park, Kim, and Yeoman (2018) with particular attention to the European and North American contexts (Lyon, 2013).

In contrast, little attention has been paid to agritourism and related practices in developing countries where the raw materials for the long and complex food and beverage supply chains are the major source of income for smallholder farmers (Hartmann, 2011; Li, Wang, \& Chan, 2014). These smallholder farmers have also been defined as vulnerable stakeholders (Candelo, Casalegno, Civera, \& Mosca, 2018; Dawkins, 2014; Derry, 2012). Torres and Momsen (2011) pointed out that in developing countries, to some degree, there has always been a cultural barrier among communities that depend entirely on agriculture to opening themselves up to the creation of agriculture-related services (e.g., food tourism), for fear that such involvement would detract farmers and cultivators from the land. However, one can observe changes, still in the early stages, in the tea and coffee supply chains that have broadened their scope and extended to tea or coffee tourism-related activities (Anbalagan \& Lovelock, 2014; Cheng et al., 2012; Gilmore \& Pine, 2002; Lyon, 2013; Pine, Pine, \& Gilmore, 1999). This development raises a few questions: Can agritourism in developing areas become the key source for their growth? If yes, what would be the benefits for local communities and tourists?

These questions become even more legitimate if we consider that within the framework of the Sustainable Development Goals (SDGs), the World Tourism Organization sees the benefit of agritourism in "complement[ing] traditional agricultural activities. The resulting rise of income in local communities can lead to a more resilient agriculture while enhancing the value of the tourism experience" (United Nations World Tourism Organization [UNWTO], 2015, p. 2).

Our study is tailored to coffee agritourism in coffee-growing countries to attempt a response to the questions raised above. The choice of coffee industry as the object of our investigation is driven by three key reasons. First, the coffee industry is experiencing an increasing coffee consumption globally with an increase of $5.9 \%$ in exports from October 2016 to July 2017, reaching 10,193 million bags sold (International Coffee Organization [ICO], 2017). Second, very few studies on coffee tourism provide insights on how coffee-growing destinations that have opened their farms and plantations to tourists are becoming commercially successful or on how to solve some of the social and environmental issues that these countries are experiencing (Anbalagan \& Lovelock, 2014). Third, the coffee industry needs to diversify the activities at the upper end of the supply chain to reduce the risk connected with the younger generations abandoning agriculture in general and coffee plantations in particular. Hence, tourism-related activities can become an appealing way to keep the human resources on the land. Furthermore, many coffee-growing communities are already increasing their engagement in sustainable projects conducted through social alliances (as defined by Berger, Cunningham, \& Drumwright, 2004) with coffee roasters and nongovernmental organizations (NGOs). Such partnerships seek to encourage local community empowerment, entrepreneurship development, environmental sustainability, and coffee excellence so that the entire supply chain may benefit (Candelo et al., 2018; Civera, 2018; Jamali, Yianni, \& Abdallah, 2011; Potts, 2003).

Our study output is a theoretical framework that describes the potential benefits of coffee agritourism for both local communities and tourists. The framework is the result of an iterated process based on theory (Corbin \& Strauss, 1990), including literature review, findings from an existing case study on coffee tourism development in Costa Rica, interviews and surveys with different stakeholders in the coffee industry.

The remainder of the article is structured as follows. The theoretical background section explains the characteristics of agritourism and coffee tourism in developing countries. The methodology section illustrates the procedures employed in our analysis. The discussion section contains the insights from the case study, the interviews, and the survey and it describes the theoretical framework we have developed as the output of our research. The final section presents the conclusions, research implications, and future directions.

Theoretical Background Agritourism in Developing Countries

Although food has had a long cultural and commercial tradition and implication in tourism and has 
been a destination choice for many years in developed countries (Lee, Alexander, \& Kim, 2014), in developing and emerging countries the interest in food and agriculture as the reason for traveling is more recent (Bianchi, 2018; Kumar, Kumar, Patel, \& Stauvermann, 2018) and has been accompanied by increased tourism in Africa, Asia, India, and Central and Latin America.

Most communities in these countries are agriculture dependent and oriented to increasing productivity as working the land is the main source of income. In such a context, all efforts are directed towards primary and secondary production, while the services development, including tourism activities, has been overlooked to reinforce income security since farmers have always seen services as a potential threat to the land (Torres \& Momsen, 2011). Especially during the 1960s and 1970s, scholars debated on whether tourism could put other sectors, particularly agriculture, at risk by favoring the competition for land and labor.

However, despite agri-food tourism in developing countries not being so well established and the relationship between tourism and agriculture being quite complex in these countries (Rogerson, 2012), some contemporary studies have shed light on the challenges of agri-food tourism development and have encouraged the creation of new business activities relating to agritourism as a way to alleviate poverty-increase income, attract investments, and diversify to benefit communities and future generations (Meyer, 2007; Torres \& Momsen, 2004; Vanegas, Gartner, \& Senauer, 2015).

One of the major issues confronting developing countries about tourism in general, and food tourism in particular, is the negative image perception by tourists (Echtner \& Prasad, 2003). Building a destination image based on agricultural specificities can help moderate some of the bad stereotypes associated with such countries, especially in the current food scenario that is dominated by consumers and tourists interested in the origins, the culture, and the source of food and beverage items (Adam et al., 2016; Saitone \& Sextone, 2017). We believe that some of the factors that Beerli and Martin (2004) claimed to positively influence a destination image might work in a developing context too: (i) the presence of natural resources and raw materials typically grown or extracted in developing countries can provide tourists a direct link to the source of their food and increase the uniqueness of their agri-food tourism experience; (ii) the natural environment can create a special atmosphere of the place, which becomes recognizable for its topography and makes the food more attractive in the mind of the tourists (Santana \& Sevilha Gosling, 2018; Taylor, 2005); (iii) the culture, in which agriculture can be seen as a legacy of the local people (Rogerson, 2012).

Creating a synergistic relationship between tourism and agriculture is key to spreading the awareness of the cultural roots and reinforcing a cultural identity among the communities and the tourists as a destination image (Anbalagan \& Lovelock, 2014; Donert \& Light, 1996; Ekinci, Sirakaya-Turk, \& Baloglu, 2007; Ekinci, Sirakaya-Turk, \& Prediado, 2013; Jansen-Verbeke, 2009). In developing countries, where farmers are frequently poor and hence more vulnerable (Torres \& Momsen, 2004), developing agritourism projects can attract investments, improve infrastructure, and enhance the quality of life and work. It is not only about a potential increase in income that will lead to a greater economic sustainability through a more resilient agriculture (Echtner \& Ritchie, 1993; Torres \& Momsen, 2011; UNWTO, 2015). It is also about greater social inclusion and attention to environmental matters to build a sustainable destination image, consistent with sustainable tourism and shifting of food from a commodity to a social activity that positively affects social, health, and environmental issues (Zepeda \& Reznickova, 2017). If the effect of climate change on cultivations around the world is considered, then agri-food touristic activities could be a way to increase the awareness of both farmers and tourists towards possible solutions for environmental issues and maybe even cooperate for effective responses (Dogru, Bulut, \& Sirakaya-Turk, 2016; Sun et al., 2011), because the quality of the environment is fundamental to tourism (Girling, Gordy, \& Lanier, 2015).

\section{Coffee Lands: A Growing Opportunity for Tourism}

Coffee is the second most traded commodity in the world and has a long and complex supply chain that involves smallholder farmers cultivating and extracting coffee crops in developing countries. Roughly 25 million people worldwide base their livelihoods on coffee and cultivate small land 
holdings, while facing various daily social, economic, and environmental challenges (Petchers \& Harris, 2008; Watson \& Achinelli, 2008).

First, most farmers working at the upper end of the coffee supply chain deal with imbalanced information and resources - limited income, skills, knowledge, and tools - in comparison to other stakeholders in the coffee supply chain, such as traders, retailers, coffee roasters, and manufacturers (Loconto \& Simbua, 2012). The information and resources asymmetry lowers the decision-making powers of farmers and could lead to wrong choices affecting coffee quality and productivity, increasing the vulnerability and marginalization of farmers (Candelo et al., 2018; Dawkins, 2014; Derry, 2012) and ultimately putting the entire supply chain at risk. To mitigate these risks, we assist in the expansion of sustainable or cooperation projects in the form of alliances among farmers' cooperatives, local NGOs, and coffee roasters to design and implement empowerment actions addressed to farmers, their families, and future working generations. The objective of these empowerment actions is to enable farmers to be independent and make informed decisions that will benefit their business, environment, their society, their children, and the entire coffee business (Candelo et al., 2018). Some of these empowerment actions consist of, for example, training activities to increase the knowledge and skills of farmers on climate change issues, income and expenditures in society, inclusion of women in the coffee business, and farmer awareness of coffee quality, technical, and negotiation skills. They also involve activities to support farmers' associations and cooperatives to strengthen their bargaining and advocacy power and advisory services to support the creation of new enterprises (Civera, 2018). Previous studies have demonstrated in a similar context - the tea tourism - that without adequate planning and cooperation among stakeholders, initiatives of tourism enhancement are most likely to fail (Cheng et al., 2012). Developing a cooperative strategic posture (Strand \& Freeman, 2015) is essential for increasing the engagement of vulnerable stakeholders in their communities and their lands and to motivate them to create new business activities (Van Niekerk, 2014).

Second, the issue of new business development is crucial in the coffee supply chain because in most communities that depend on coffee crops the younger generation is moving away from agriculture. Such a situation jeopardizes not only the sustenance of the farming families but also the survival of the entire coffee business in the future. In this regard, the cooperation or sustainable projects carried out by NGOs and coffee roasters to empower farmers and their families are tailored to the needs of the younger generation, with a goal of creating new service organizations (Civera, 2018). Such organizations are intended to become a working place for the youth to support the core coffee business by improving technical skills of farmers through key information dissemination and network creation among farmers and groups of local experts. This is consistent with Ritchie and Crouch's (2003) view that diversification is essential for competitiveness and sustainability. In this regard, we argue that establishing tourism activities relating to coffee can be an effective diversification strategy to enhance the coffee appeal for tourists and locals in terms of agricultural techniques, culture, and heritage. Involving small producers and the youth in activities correlated to coffee cropping means establishing inclusive business models that incorporate needs of local communities, such as employment, and providing tourists with new images, perceptions, and experiences of the country (Brenes, Montoya, \& Ciravegna, 2014; Proctor \& Vorley, 2008). In Haiti and the Dominican Republic, the design of the ecotourism project called the "Coffee Route" or La Ruta del Café is an expression of the will of the community and its partners (NGOs and coffee roasters) to make coffee-growing lands attractive tourist destinations through the empowerment and the involvement of farmers who become new local sustainable entrepreneurs (Hung, Sirakaya-Turk, \& Ingram, 2011; Sirakaya-Turk, Ekinci, \& Kaya, 2008).

Third, most coffee production areas lack proper hotel infrastructure for tourists to be able to have a decent and valuable experience and this is one of the biggest challenges for development of coffee tourism and agritourism in developing countries (Gauci, Gerosa, \& Mwalwanda, 2002). However, some of the empowerment actions designed to improve the coffee production system and technical work within the plantations are attracting investments to improve the infrastructure systems also. Coffee tourism can increase investments and money circulation for reinvestment in the area. We argue that establishing coffee-based tourism activities can be a way to further empower 
vulnerable stakeholders and their families and to facilitate the spread of a cooperative strategic posture to attract investments, to sell coffee more effectively, and to establish balanced relationships with tourists.

The few studies developed around coffee-based tourism show that farmers can take advantage of the increasing growth of coffee demand and consumption worldwide and coffee-related tourism services have an "enormous value added potential" (Anbalagan \& Lovelock, 2014) that is yet to be fully realized (Jolliffe, 2010). For example, in Vietnam, coffee is considered to be a local product and its production, together with its rituals, has started to attract tourism (Jolliffe \& Aslam, 2009).

Jolliffe (2010) has identified three types of coffee tourism: (i) visits to coffee-producing destinations; (ii) experiences of coffee culture places; (iii) visits to coffee history destinations. This study focuses on the coffee-producing destinations defined as those countries where the coffee produced is recognizable for its unique location (Anbalagan \& Lovelock, 2014). We can consider as examples the coffee finca tourism in Colombia, the Buon Ma Thuot annual coffee festival in Vietnam, the coffee route in Haiti and the Dominican Republic, and the famous coffee farms tours in Costa Rica since the 1990s (Jolliffe, 2010; Jolliffe \& Aslam, 2009).

\section{Methodology}

We employed a qualitative empirical methodology following the procedures established in theory (Corbin \& Strauss, 1990). The information gathering was conducted through an iterated process involving literature review, based on which we propose some early arguments, and the elaboration of a case study of coffee tourism in Costa Rica to test and refine those arguments (Eisenhardt \& Graebner, 2007).

The four arguments or hypotheses that we propose are the following:

1. Coffee agritourism can contribute in creating a destination image based on natural resources, coffee culture, and a special atmosphere created by providing tourists a direct link to the source of what they consume at home.

2. Coffee agritourism can boost economic, social, and environmental sustainability while encouraging sustainable tourist consumption and increasing tourist awareness of local social, economic, and environmental matters.

3. Coffee agritourism can be a lever for coffee activities diversification and increasing the business continuation through inclusive business models while providing tourists with new images, perceptions, and experiences of a country.

4. Coffee agritourism can be a way to further empower vulnerable stakeholders and their families and favor cooperation to obtain economic and social advantages and to promote coffee among tourists more effectively.

The case study we used was based on: (a) Costa Rica coffee tourism project documents available online, and (b) semistructured interviews (Russel Bernard, 1988) conducted face-to-face and on Skype with a Costa Rica-born entrepreneur who now runs a theme blog on coffee culture and tourism in Costa Rica and is also a local coffee tour operator and the manager of sustainability for a major Italian coffee roaster involved in cooperation projects of empowerment in coffee producing countries. We decided to use the case study of Costa Rica as a coffee tourism destination because it is seen as a benchmark from the early 1990s when a pilot project to test the viability of tourism to enhance coffee farmers income was implemented (Harvey \& Kelsay, 2010; Hearne \& Salinas, 2002). Furthermore, we conducted a survey among a sample of 200 coffee tourists, actual and potential, from various European countries, such as Belgium, England, France, Germany, Greece, Italy, the Netherlands, Portugal, and Spain. We enlisted the support of a professional tour operator in the identification of the actual and potential coffee tourist targets to interview. We selected our sample population from blogs and social media groups dedicated to coffee tourism (for the actual coffee tourists) and from blogs and social media groups devoted to travelers to coffee-producing countries like Costa Rica, Vietnam, Haiti, and the Dominican Republic, which are usually visited for reasons other than a coffee experience (for the potential coffee tourists).

We triangulated all the data collected, quotes from respondents, and a schematic view (Arnold \& Fischer, 1994; Lau \& Woodman, 1995; Stake, 2013; Yin, 2013) to model the benefits of coffee 
tourism for both vulnerable stakeholder communities and tourists in a theoretical framework.

Data collection for the case study elaboration was conducted on multiple occasions over a period of 5 months starting March 2017. Interviews with the entrepreneur from Costa Rica and the coffee roaster's manager were conducted within a period of 3 months starting June 2017 and each person was interviewed three times, producing a total of six interviews. Between September and November 2017, survey participants were asked to respond to an online questionnaire consisting of a mix of multiple choice and open-ended questions. Only 126 responses were considered valid as some of the respondents could neither be considered actual nor potential coffee tourists, even though we picked them on dedicated blogs and social media groups.

On the one hand, the interviews of the sustainability manager were prepared to investigate the perceptions and ideas on the potential of coffee tourism. As a representative of a major Italian coffee roaster, we wanted to know if big corporations sourcing their coffee from developing countries see any benefits in developing tourism activities based on coffee in such countries. Also, we asked him about the nature and extent of roasters' involvement in tourism activities and if roasters perceive the phenomenon would increase the chances of a general improvement of the coffee business, in terms of social and working advantages for farmers, business continuation, and increasing tourists' awareness of coffee. The interviews with the local entrepreneur were aimed at gathering insights on the potential of coffee tourism for the local community in terms of social, economic, and environmental advantages.

On the other hand, the survey of actual and potential coffee tourists was designed to obtain first evidence of their awareness of this kind of agritourism and to gather insights on their previous or desirable experiences relating to coffee tourism. Furthermore, the survey aim was to collect preferences of participants for the kind of activities that they would like to be involved in when visiting a coffee-producing country. We also asked them to rank (using a Likert scale from 0 to 5 ) the relevance of some topics-sustainability, improvement of infrastructure, farmer empowerment, diversification of the tourism experience - that they think would benefit both their experience and the coffee community well-being at the same time.

\section{Results and Discussion}

\section{Coffee Tourism in Costa Rica}

Costa Rica is well known for its high quality golden grain (as defined by the Costa Rica Institute of Coffee ICAFE) and was chosen as a case study because it was one of the first countries to develop the so-called nature tourism or ecotourism based on sustainability and traditional coffee plantations and is still one of the leaders in the agritourism sector (Harvey \& Kelsay, 2010; Hearne \& Salinas, 2002).

In the late 1990s, a group of consultants were asked to investigate and propose solutions to fix the coffee crisis in Central America, which resulted in raw material price issues and shrinking coffee plants. Some of those crises evolved into opportunities for some territories, among which Costa Rica stands out (Harvey \& Kelsay, 2010). From the start of 2000, a pilot project was running in Costa Rica with the aim of testing the feasibility of establishing and developing coffee tourism destinations. The challenge was to figure out if coffee tourism could be a good opportunity for new and diversified income generation that could benefit the land and create economic, social, and environmental value for the community, including a higher awareness of the coffee business potential. This pilot program was run in Los Santos, in South Costa Rica, where 30\% of Costa Rican small coffee producers are located and $6.5 \%$ of the famous Costa Rican finest Tarrazú is produced (Harvey \& Kelsay, 2010). Los Santos represented, at the beginning of this test, a Costa Rican area where tourism was underdeveloped, in comparison to other surrounding areas. The experiment was well accepted by locals, probably because of the government's initiatives in communicating and improving the perception of coffee business diversification, which helped influence farmers toward coffee tourism development. The first benefit for farmers was the increase in income that they would receive from the establishment of coffee routes for tourists. The program was, in fact, tailored to bringing tourists around the local areas for hiking, tasting, and witnessing a live experience of coffee 
production. The experiment brought up a very relevant detail in further development and diversification activities in the coffee-producing areas-like wine, the taste and organoleptic characteristics of coffee depends on the land where it grows and this could lead coffee lovers/consumers and tourists to experience different kinds of coffee beans and increase their awareness of coffee origins. This diversification strategy is said to have contributed to provide tourists with variegated experiences of Costa Rica and reduced the bad stereotypes associating with Costa Rica in the past.

Much has changed since the pilot project was conducted in Costa Rica. Now the country is strongly linked to coffee agritourism, acknowledged by the local government and institutions as a key source for economic and social development. When analyzing the Costa Rica plantation tours available on the web through providers like Ecogetaways, TripAdvisor, and Culture Trip, and institutions such as the Costa Rica Institute of Coffee (ICAFE), the emerging coffee tourism model offers features that confirm some of our arguments on the benefit of coffee tourism development. We investigated the coffee tourism offer of 27 plantation tours in total - from the oldest, the most traditional, and family-owned Finca Rosa Blanca (appearing in all web searches) to the more modern plantations that respect tradition but are run by entrepreneurs like the Naturalba company, located in Turrialba. Our content analysis of their documents and website information, including the comments and online tourist reviews, demonstrates that those 27 coffee tours provide common benefits to their communities and tourists.

First, all tours are designed to provide a sustainable experience to tourists. Farm owners have to declare that their plantations are cultivated in an environmental friendly way and that the outcome of their production is fair-trade, ecofriendly, and organic coffee, sometimes even certified, by Rainforest Alliance, for instance. From the analysis of such coffee tour offers, one strength that emerged was the awareness that farmers demonstrate the importance of farming practices and the knowledge of how to improve coffee quality, reduce the risk of climate change, and improve the productivity with less harm to the environment. Costa Rica plays a key role in sustainability - the country is number one on the United Nations World Happiness Report and one explanation for that is Costa Rica provides its inhabitants and tourists with strong social bonds, a clean environment, and investments in education. As the local entrepreneur commented, the demand for coffee places as tourism destination is expected to grow in the future and this phenomenon can bring further advantages to farmers in income only if the coffee production meets the high standards of sustainability and is consistent with the naturalness of Costa Rica. The interviewee stressed that tourists look for more sustainable consumption models and try to be more environment friendly:

I imagine that the future size of coffee tourism industry can reach at least one third of the wine tourism which, according to the World Tourism Organization data, started about 30 years ago and makes today about $\$ 50$ billion per year. ... I have seen that there is a growing demand for visiting countries where coffee grows at one condition: that tourists can experience the real coffee rituals and can make a contribution in terms of social and environmental development as well. . . . (Local Entrepreneur)

Second, the awareness of farmers and business owners of their business and sustainable operations is reflected in the common attitude toward tourists. Learning is the principle behind each analyzed tour. During the tours, tourists experience the entire process of coffee making, from cropping to harvesting, and are taught the main steps, with a focus on sustainable practices-for instance, the water reuse process. In the Doka Estate Plantation and Coffee Tour, the coffee processing plant was declared an Architectural Heritage for Humanity in 2003 by UNESCO. Many of these tours establish direct connections with coffee experts and participate in demonstrating how gourmet coffee is tested and rated. Furthermore, some farms offer the opportunity to pick coffee berries and/or provide coffee places where tourists can practice their skills in making their own coffee with the local produce. Learning objectives are not just tailored to the coffee process, production, and culture; tours also provide an opportunity to increase tourist awareness of culture, traditions, and daily life in Costa Rica. As the roaster's manager confirmed, most empowerment actions addressed to farmers seek to develop farmer skills and spread the knowledge 
on sustainable issues. In coffee tourism, this aspect is even more crucial because farmers become the trainers for tourists:

I see the development of coffee tourism as an important step of empowerment that allows farmers to spread the knowledge they acquired and to feel more powerful and independent entrepreneurs. (Sustainability Manager)

Third, most coffee plantations are family owned and involve farmers and their families in the cultivation of the plantations and in the organization of the tours and managing of the lodges. Some other coffee tours and farms are owned by larger farmer cooperatives, such as the Monteverde managed by the Cooperative of Santa Elena, that support farmers and their families. In other cases, the farms and tours are cooperatives themselves and deal with all aspects of production and tourism management.

The interviews of both the sustainability manager and the local entrepreneur highlight the need and the benefit of cooperation, from two different but convergent perspectives:

We take active part in sustainability projects to empower farmers and one constant activity that we undertake is the training through capacity building to facilitate entrepreneurship, business skills development and favor cooperation. . . . Establishing a cooperative attitude is key to successful new enterprises formation. ... Through coffee tourism development farmers diversify and strengthen their business portfolio by including members of their families and guaranteeing business continuation. . . . Coffee tourism favors both their emancipation and their cooperation. (Sustainability Manager)

Farmers' cooperatives are an effective solution to manage diversified businesses. What the government strived for, here in Costa Rica, was favoring the dialogue and sharing of practices among farmers to increase the chances of networking and association. (Local Entrepreneur)

It was very common for coffee plantations to further extend and diversify their tours by combining the coffee experience with other productions. In at least 10 cases, tourists can also visit cocoa and other plantations, such as mango, guava, lime, water apple, banana, and orange. The local entrepreneur outlined the importance of business diversification, especially from the point of view of tourists:

\begin{abstract}
As a local tour operator, I witness a growing demand for coffee tours by tourists who wish to experience anything concerning organic food and enjoy visiting farms that can expose them to multiple inputs and where they probably can spend the entire day eating and drinking products directly from the land, expression of our culture. (Local Entrepreneur)
\end{abstract}

\section{Framework of Coffee Tourism Benefits}

By merging the insights gathered from the case study and the interviews of the local entrepreneur in Costa Rica and the Italian roaster's sustainability manager with the results of the survey conducted among tourists, we could draw a theoretical framework that illustrates the coffee tourism benefits for both local farmers and tourists.

Overall, we confirm that coffee tourism cannot succeed without adequate cooperation among stakeholders (Cheng et al., 2012) and we also support the idea that coffee tourism can be an opportunity to strengthen a cooperative strategic posture (Strand \& Freeman, 2015) among farmers and between farmers and other stakeholders, including tourists. The local entrepreneur who we interviewed argued that cooperation is both a prerequisite and a benefit of a well-planned coffee tourism initiative-forming associations and federations of coffee producers involved in tourism activities is a way for facilitating direct interaction between farmers and tourists and thereby enhance the quality and the value of the relationship. The results from the survey show that $85 \%$ of tourists (regardless of whether actual or potential) evaluated farmer empowerment and cooperation as the most relevant benefit (scoring 4 and 5) of coffee tourism. The same percentage of tourists declared that the associated advantage for them (tourists) lies in the improved quality of relationships, which they want to establish directly with knowledgeable farmers, just like they do with wine makers, for instance. The fact that tourists wish to have a more authentic and direct relationship with the coffee producer will contribute in shaping new images, perceptions, and experiences of the country (Brenes et al., 2014; Proctor \& Vorley, 2008). Seventy percent of respondents assigned a high ranking 
(from 4 to 5) to the improvement of infrastructure as one of the main benefits of coffee tourism for locals. This confirms that poor infrastructure system, considered one of the main limitations of coffee tourism development (Gauci et al., 2002), can be improved by constant empowerment and cooperation of farmers, by augmenting their power to attract investments, in a virtuous circle. Additionally, poverty can be alleviated through the same mechanism (Vanegas et al., 2015).

Furthermore, a remarkable result emerging from the survey with tourists is that $90 \%$ of tourists who declared to have visited the coffee producing country to experience coffee tours ranked sustainability as the main benefit (scoring 5) of coffee tourism, both for farmers and tourists, confirming the increasing social and environmental role of food and tourism (Girling et al., 2015; Sirakaya-Turk et al., 2014; Zepeda \& Reznickova, 2017).

A majority of potential tourists $(75 \%)$ declared that the second perceived benefit of coffee tourism for local communities is the generation of new income and $60 \%$ of the respondents relate the advantages of tourism to include other sustainable and organic products.

Costa Rica has certainly succeeded in creating a destination image based on coffee and we confirm that this is one of the main benefits of coffee tourism for the local community. However, our findings suggest that there is still a long way to go before other developing countries can emulate the Costa Rica model. Although most respondents declare that building a destination image of sustainable coffee might reduce some of the bad stereotypes because of increased attention to food and beverage source and culture (Adam et al., 2016; Saitone \& Sextone, 2017), some (40\%) believe that coffee-producing countries can build their image just on coffee production. The remaining stated that a destination image can be built on coffee and therefore is a benefit of coffee tourism only, accompanied by specific characteristics that make the coffee-producing area more appealing, such as organic and sustainable outputs.

Figure 1 illustrates the framework of coffee tourism benefits for farmers (internal circle) and linked benefits for tourists (external circle).

\section{Conclusions, Implications, and Future Directions}

This study provides further theoretical insights into the literature on food agritourism in developing countries, which has been underinvestigated (Lyon, 2013; Torres \& Momsen, 2011). Despite the growing agri-food tourism activities, such as tea and coffee in developing countries (Anbalagan

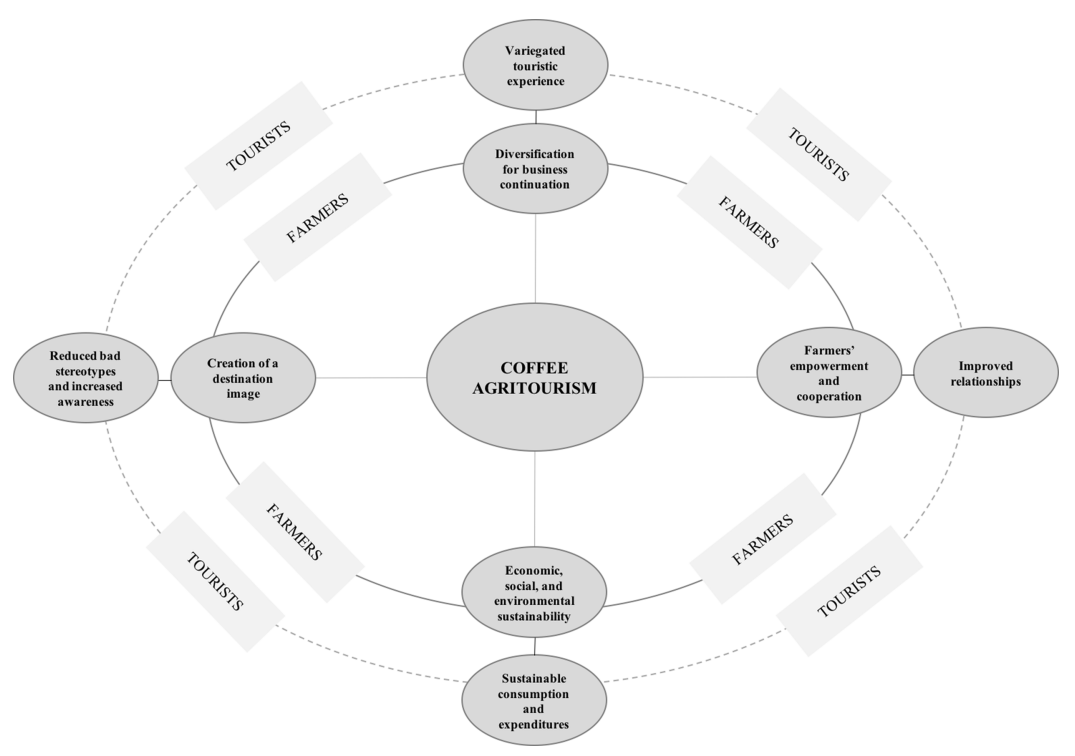

Figure 1. Theoretical framework of coffee tourism benefits. 
\& Lovelock, 2014; Cheng et al., 2012; Gilmore \& Pine, 2002; Lyon, 2013; Pine et al., 1999), few studies have explored the understanding of the potentials and benefits of such types of tourism for farmers, their families, and local communities, considered the vulnerable stakeholders, and tourists. Our theoretical framework is based on literature review, a case study of Costa Rica, and multiple stakeholder perspectives to attempt to fill this gap and provide theoretical assumptions of the benefit of coffee tourism for local vulnerable stakeholders and communities in developing countries and actual and potential coffee tourists.

Through our study we also highlight the potentials of coffee tourism and hope to contribute towards increasing awareness of the possible economic, social, and environmental implications and strengthen the role that roasters, NGOs, and local institutions can play in favoring empowerment and cooperation among farmers and between farmers and coffee stakeholders to develop coffee tourism.

We plan to extend the scope of this study to other coffee-producing countries and use institutional theory to compare the setting of the country to test our framework and point out how the tourism benefits for locals and tourists can be achieved more effectively.

\section{References}

Adam, B. D., Holcomb, R., Buser, M., Mayfield, B., Thomas, J., O’Bryan, C. A., . . . Ricke, S. C. (2016). Enhancing food safety, product quality, and value-added in food supply chains using whole-chain traceability. International Food and Agribusiness Management Review, 19(A), 191-213.

Anbalagan, K., \& Lovelock, B. (2014). The potential for coffee tourism development in Rwanda-Neither black nor white. Tourism and Hospitality Research, 14(1-2), 81-96.

Arnold, S. J., \& Fischer, E. (1994). Hermeneutics and consumer research. Journal of Consumer Research, 21(1), 55-70.

Beerli, A., \& Martin, J. D. (2004). Factors influencing destination image. Annals of Tourism Research, 31(3), 657-681.

Berger, I. E., Cunningham, P. H., \& Drumwright, M. E. (2004). Social alliances: Company/nonprofit collaboration. California Management Review, 47(1), 58-90.

Bianchi, C. (2018). Exploring the attractiveness of Chile as a vacation destination for international tourists. Tourism Analysis, 23(3), 351-364.
Brenes, E. R., Montoya, D., \& Ciravegna, L. (2014). Differentiation strategies in emerging markets: The case of Latin American agribusinesses. Journal of Business Research, 67(5), 847-855.

Candelo, E., Casalegno, C., Civera, C., \& Mosca, F. (2018). Turning farmers into business partners through value cocreation projects. Insights from the coffee supply chain. Sustainability, 10(4), 1018.

Cheng, S., Hu, J., Fox, D., \& Zhang, Y. (2012). Tea tourism development in Xinyang, China: Stakeholders' view. Tourism Management Perspectives, 2, 28-34.

Civera, C. (2018). Integrated company responsibility in the food and beverage industry. Giappichelli, Italy.

Corbin, J. M., \& Strauss, A. (1990). Grounded theory research: Procedures, canons, and evaluative criteria. Qualitative Sociology, 13(1), 3-21.

Dawkins, C. E. (2014). The principle of good faith: Toward substantive stakeholder engagement. Journal of Business Ethics, 121(2), 283-295.

Derry, R. (2012). Reclaiming marginalized stakeholders. Journal of Business Ethics, 111(2), 253-264.

Dogru, T., Bulut, U., \& Sirakaya-Turk, E. (2016). Theory of vulnerability and remarkable resilience of tourism demand to climate change: Evidence from the Mediterranean Basin. Tourism Analysis, 21(6), 645-660.

Donert, K., \& Light, D. (1996). Capitalizing on location and heritage: Tourism and economic regeneration in Argentiere La Basse, High French Alps. In L. Harrison, \& W. Husbands (Eds.), Practicing responsible tourism (pp. 193-215). Brisbane, Australia: Wiley.

Echtner, C. M., \& Prasad, P. (2003). The context of third world tourism marketing. Annals of Tourism Research, $30(3), 660-682$.

Echtner, C. M., \& Ritchie, J. B. (1993). The measurement of destination image: An empirical assessment. Journal of Travel Research, 31(4), 3-13.

Eisenhardt, K. M., \& Graebner, M. E. (2007). Theory building from cases: Opportunities and challenges. The Academy of Management Journal, 50(1), 25-32.

Ekinci, Y., Sirakaya-Turk, E., \& Baloglu, S. (2007). Host image and destination personality. Tourism Analysis, 12(5-6), 433-446.

Ekinci, Y., Sirakaya-Turk, E., \& Preciado, S. (2013). Symbolic consumption of tourism destination brands. Journal of Business Research, 66(6), 711-718.

Ellis, A., Park, E., Kim, S., \& Yeoman, I. (2018). What is food tourism? Tourism Management, 68, 250-263.

Gauci, A., Gerosa, V., \& Mwalwanda, C. (2002). Tourism in Africa and the multilateral trading system: Challenges and opportunities. A background paper for the Economic Commission for Africa.

Gilmore, J. H., \& Pine, B. J. (2002). The experience is the marketing. Louisville, KY: BrownHerron Publishing.

Girling, R., Gordy, H., \& Lanier, P. (2015). The good company: Sustainability in hospitality, tourism, and wine. New York, NY: Business Expert Press.

Harvey, B., \& Kelsay, D. (2010). La Ruta del Cafe and Los Santos coffee tourism: A Central America project to 
develop coffee-related tourism to augment coffee families' incomes. In L. Jolliffe (Ed.), Coffee culture, destinations and tourism (pp. 197-220). Bristol, UK: Channel View Publications.

Hartmann, M. (2011). Corporate social responsibility in the food sector. European Review of Agricultural Economics, 38(3), 297-324.

Hearne, R. R., \& Salinas, Z. M. (2002). The use of choice experiments in the analysis of tourist preferences for ecotourism development in Costa Rica. Journal of Environmental Management, 65(2), 153-163.

Hung, K., Sirakaya-Turk, E., \& Ingram, L. J. (2011). Testing the efficacy of an integrative model for community participation. Journal of Travel Research, 50(3), 276-288.

International Coffee Organization. (2017). Annual review 2016/17. Retrieved from https://www.ico.org/documents/cy2017-18/annual-review-website-e.pdf

Jaffee, D. (2014). Brewing justice: Fair trade coffee, sustainability, and survival. Berkeley, CA: University of California Press.

Jamali, D., Yianni, M., \& Abdallah, H. (2011). Strategic partnerships, social capital and innovation: Accounting for social alliance innovation. Business Ethics: A European Review, 20(4), 375-391.

Jansen-Verbeke, M. (2009). The territoriality paradigm in cultural tourism. Tourism, 19(1-2), 25-31.

Jolliffe, L. (Ed.). (2010). Coffee culture, destinations and tourism (Vol. 24). Bristol, UK: Channel View Publications.

Jolliffe, L., \& Aslam, M. S. (2009). Tea heritage tourism: evidence from Sri Lanka. Journal of Heritage Tourism, 4(4), 331-344.

Kumar, N., Kumar, R. R., Patel, A., \& Stauvermann, P. J. (2018). Exploring the effects of tourism and economic growth in Fiji: accounting for capital, labor, and structural breaks. Tourism Analysis, 23(3), 391-407.

Lau, C. M., \& Woodman, R. W. (1995). Understanding organizational change: A schematic perspective. Academy of Management Journal, 38(2), 537-554.

Lee, K. H., Alexander, A. C., \& Kim, D. Y. (2014). A study of geographical distance groups on length of visitors' stay at local food festival destinations. Journal of Vacation Marketing, 20(2), 125-136.

Li, D., Wang, X., Chan, H. K., \& Manzini, R. (2014). Sustainable food supply chain management. International Journal of Production Economics, 152(0), 1-8.

Loconto, A. M., \& Simbua, E. F. (2012). Making room for smallholder cooperatives in Tanzanian tea production: Can Fairtrade do that? Journal of Business Ethics, 108(4), 451-465.

López-Guzmán, T., Sánchez-Cañizares, S., \& Pavón, V. (2011). Community-based tourism in developing countries: A case study. Tourismos, 6(1).

Lyon, S. (2013). Coffee tourism and community development in Guatemala. Human Organization, 72(3), 188-198.

Meyer, D. (2013). Pro-poor tourism: From leakages to linkages. A conceptual framework for creating linkages between the accommodation sector and 'poor' neighbouring communities. Current Issues in Tourism, 10(6), 558-583.

Petchers, S., \& Harris, S. (2008). The roots of the coffee crisis. Confronting the coffee crisis: Fair trade, sustainable livelihoods and ecosystems in Mexico and Central America. Cambridge, MA: MIT Press.

Phillip, S., Hunter, C., \& Blackstock, K. (2010). A typology for defining agritourism. Tourism Management, 31(6), 754-758.

Pine, B. J., Pine, J., \& Gilmore, J. H. (1999). The experience economy: Work is theatre \& every business a stage. Brighton, MA: Harvard Business Press.

Plummer, R., Telfer, D., Hashimoto, A., \& Summers, R. (2005). Beer tourism in Canada along the WaterlooWellington ale trail. Tourism Management, 26(3), 447-458.

Potts, J. (2003). Building a sustainable coffee sector using market based approaches: The role of multi stakeholder cooperation. Retrieved from https://www.iisd.org/pdf/ 2004/sci_coffee_background2.pdf

Proctor, F. J., \& Vorley, B. (2008). Innovation in business models and chainwide learning for market inclusion of smallholder producers. BANWA Archives (2004-2013), 5(2), 22-38.

Ritchie, J. B., \& Crouch, G. I. (2003). The competitive destination: A sustainable tourism perspective. Wallingford, UK: CABI.

Rogerson, C. M. (2012). Strengthening agriculture-tourism linkages in the developing World: Opportunities, barriers and current initiatives. African Journal of Agricultural Research, 7(4), 616-623.

Russel Bernard, H. (1988). Research methods in cultural anthropology. Thousand Oaks, CA: Sage

Saitone, T. L., \& Sexton, R. J. (2017). Agri-food supply chain: Evolution and performance with conflicting consumer and societal demands. European Review of Agricultural Economics, 1-24.

Santana, L. D., \& Sevilha Gosling, M. D. (2018). Dimensions of image: A model of destination image formation. Tourism Analysis, 23(3), 303-322.

Sharpley, R., \& Telfer, D. J. (2015). Tourism and development in the developing world. Abingdon, UK: Routledge.

Sirakaya-Turk, E., Baloglu, S., \& Mercado, H. U. (2014). The efficacy of sustainability values in predicting travelers' choices for sustainable hospitality businesses. Cornell Hospitality Quarterly, 55(1), 115-126.

Sirakaya-Turk, E., Ekinci, Y., \& Kaya, A. G. (2008). An examination of the validity of SUS-TAS in cross-cultures. Journal of Travel Research, 46(4), 414-421.

Stake, R. E. (2013). Multiple case study analysis. New York, NY: Guilford Press.

Strand, R., \& Freeman, R. E. (2015). Scandinavian cooperative advantage: The theory and practice of stakeholder engagement in Scandinavia. Journal of Business Ethics, $127(1), 65-85$.

Sun, Y., Jansen-Verbeke, M., Min, Q., \& Cheng, S. (2011). Tourism potential of agricultural heritage systems. Tourism Geographies, 13(1), 112-128. 
Taylor, P. L. (2005). In the market but not of it: Fair trade coffee and forest stewardship council certification as market-based social change. World Development, 33(1), 129-147.

Torres, R., \& Momsen, J. H. (2004). Challenges and potential for linking tourism and agriculture to achieve pro-poor tourism objectives. Progress in Development Studies, 4(4), 294-318.

Torres, R. M., \& Momsen, J. (Eds.). (2011). Tourism and agriculture: New geographies of consumption, production and rural restructuring. Abingdon, UK: Routledge.

United Nations World Tourism Organization. (2015). Tourism and the sustainable development goals. Retrieved from https://www.e-unwto.org/doi/pdf/10.18111/978928 4417254
Vanegas Sr, M., Gartner, W., \& Senauer, B. (2015). Tourism and poverty reduction: An economic sector analysis for Costa Rica and Nicaragua. Tourism Economics, 21(1), 159-182.

Van Niekerk, M. (2014). The role of the public sector in tourism destination management from a network relationship approach. Tourism Analysis, 19(6), 701-718.

Watson, K., \& Achinelli, M. L. (2008). Context and contingency: The coffee crisis for conventional small-scale coffee farmers in Brazil. Geographical Journal, 174(3), 223-234.

Yin, R. K. (2013). Validity and generalization in future case study evaluations. Evaluation, 19(3), 321-332.

Zepeda, L., \& Reznickova, A. (2017). Innovative millennial snails: the story of Slow Food University of Wisconsin. Agriculture and Human Values, 34(1), 167-178. 